\title{
Structure and morphology of magnetron sputtered CoCr thin films
}

\author{
B.G. Demczyk \\ North Campus Electron Microbeam Analysis Laboratory, Department of Materials Science and Engineering, \\ The Unirersity of Michigan, Ann Arbor, MI 48109, USA
}

Received 19 April 1991; in revised form 11 July 1991

\begin{abstract}
The growth characteristics of magnetron sputtered $\mathrm{Co}-22 \% \mathrm{Cr}$ thin films on amorphous glass or carbon substrates have been investigated utilizing transmission electron microscopy, X-ray diffraction and electrical resistivity measurements. Results indicate that the initial deposit is "amorphous", but that small crystallites form before the film reaches $5 \mathrm{~nm}$ film thickness. By $10 \mathrm{~nm}$, well oriented grains with hcp c-axis perpendicular to the film plane develop, and by $50 \mathrm{~nm}$, a columnar microstructure is evident. A distinct subgrain structure was also observed in the thinner films $(10-50 \mathrm{~nm})$, and this is reflected in the electrical resistivity. These observations cannot be accounted for by an "evolutionary selection" growth scenario, but must be related to the low surface mobility of adatoms at these low substrate deposition temperatures $\left(<50^{\circ} \mathrm{C}\right)$
\end{abstract}

\section{Introduction}

$\mathrm{CoCr}$ has been studied extensively as the leading candidate for perpendicular magnetic recording media [1,2]. Due to its relatively simple hcp crystal structure, this material also serves as a logical system for the study of microstructural development on various substrates. The development of microstructure in this system has been reported by a number of investigators [3-9]. These studies have indicated a general growth scenario in which an initial fine-grained, randomly oriented "transition layer" first forms, followed by the development of columnar grains, with their $c$-axes out of the film plane. The thickness of this "transition layer", as well as the morphology of the columns (conically expanding or straight sided) vary according to the particular deposition conditions and/or substratc matcrials utilizcd. For example, conically expanding columns and a significant transition layer in rf-sputtered $\mathrm{CoCr}$ films were reported by Lodder et al. [3] and Hwang et al. [4] for films deposited on glass and by Futamoto et al. [5], on $\mathrm{NaCl}$ substrates. Grundy et al. [6] cited similar results in de triode sputtered films deposited on glass. Conversely, Lee et al. [7] generally observed conically expanding columns and very thin transition layers in $\mathrm{dc}$ magnetron sputtered $\mathrm{CoCr}$ films on glass. Finally, Hong et al. [8] and Cura and Lenhart [9] found straight columns and no transition layer in magnetron sputtered (on $\mathrm{Si}$ or $\mathrm{SiO}_{2}$ substrates) $\mathrm{CoCr}$ films. This represents merely a sampling of the available literature on the subject. In this investigation, the development of the microstructure in $\mathrm{Co}-22$ at $\% \mathrm{Cr}$ films sputter deposited on amorphous substrates has been examined systematically and in considerably more detail than has been reported to date.

\section{Experimental}

Films were deposited onto amorphous (Corning 7059 glass or carbon) substrates using a Varian DC Magnetron (" $S$ " gun) sputtering system. Sputtering conditions included an argon pressure of one mTorr, unheated substrates $\left(T<50^{\circ} \mathrm{C}\right)$ 
and a sputtering rate of $0.25 \mathrm{~nm} / \mathrm{s}$. Thin film $(\leq 50 \mathrm{~nm})$ plan view TFM specimens were prepared by depositing directly onto carbon coated 3 mm copper grids, enabling direct TEM observation. Thicker films were deposited onto glass substrates which were mechanically thinned to about $40 \mu \mathrm{m}$, after which they were ion $(\mathrm{Ar}+)$ beam milled to electron transparency. The similarity of microstructures for thick (>50 nm) films deposited on amorphous carbon and glass substrates has been reported previously [10]. Section samples (deposited on glass) were fabricated by bonding two films face-to-face, mechanical thinning and ion beam milling. Conventional TEM (bright field imaging and selected area diffraction) as well as electron microdiffraction were performed on JEOL 2000FX, transmission elec- tron microscope, operating at $200 \mathrm{kV}$. For high resolution work, a JEOL 4000EX HREM operating at $400 \mathrm{kV}$, was employed. Electrical resistivity was determined on $0.5 \times 2 \mathrm{~cm}^{2}$ samples employing a four point probe method. These measurements were made using a current of $100 \mu \mathrm{A}$, at liquid nitrogen temperatures to minimize any $I^{2} R$ heating effects. $\mathrm{X}$-ray rocking $\left(\Delta \theta_{50}\right)$ curves were taken utilizing $\mathrm{CuK} \alpha$ radiation on a Rigaku Geigerflex diffractometer.

\section{Results}

Figure 1 shows a plan view high resolution micrograph taken from a $5 \mathrm{~nm}$ thick $\mathrm{CoCr}$ film. As shown, the majority of the area is

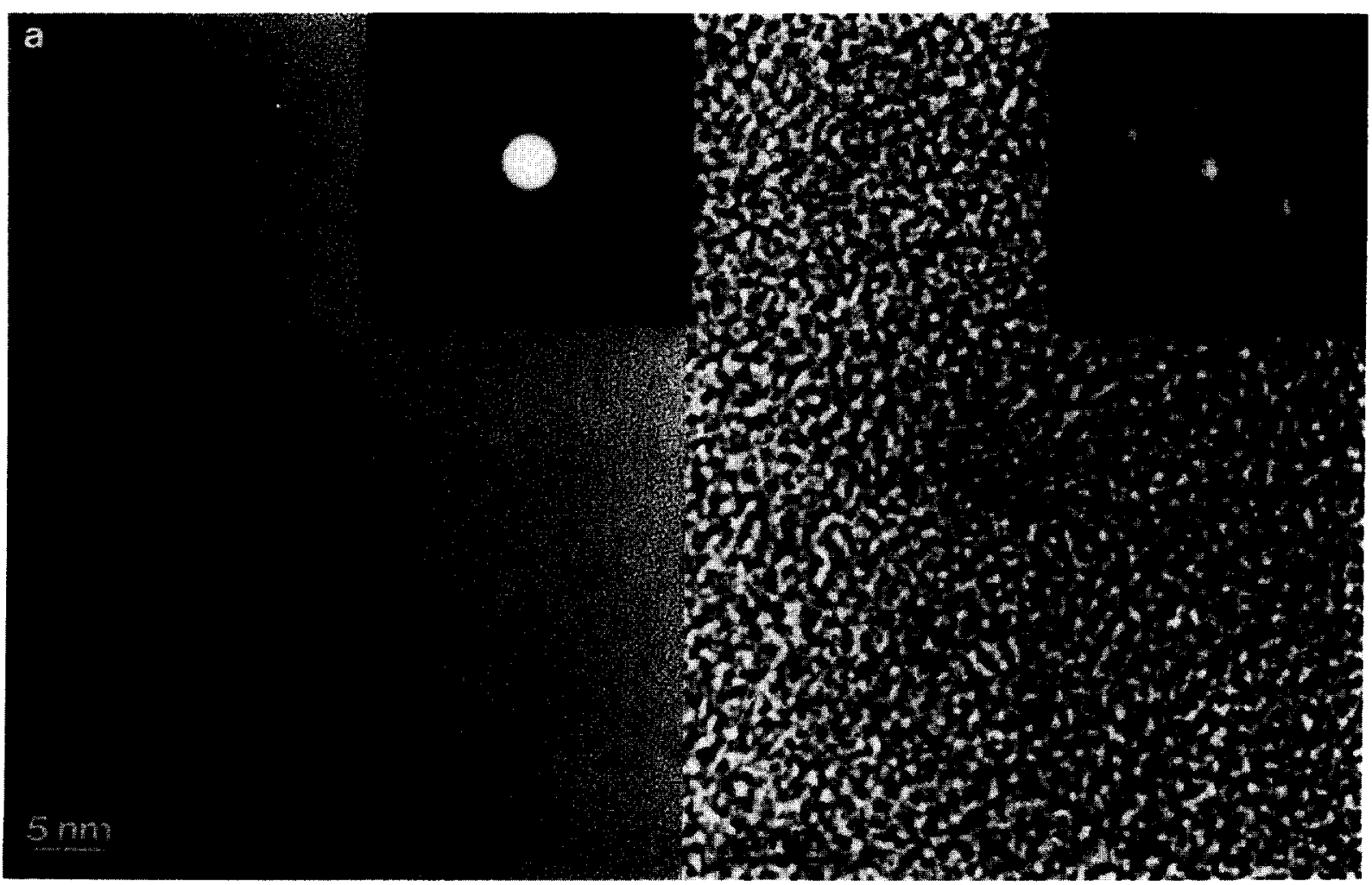

Fig. 1. (a) TEM micrograph of a $5 \mathrm{~nm}$ thick $\mathrm{CoCr}$ film. Note the presence of occasional small crystallites within the amorphous matrix. Arrow indicates one such crystallite. (b) HREM image showing a single crystallite. Inset depicts the corresponding optical diffraction pattern. 
"amorphous" even at the approximately $0.18 \mathrm{~nm}$ point-to-point resolution of the microscope. The ring pattern taken from this area (fig. 1 inset), although sharp, displays no discrete diffraction maxima and is consistent with an amorphous structure. Small $(\approx 2 \mathrm{~nm})$ crystallites are occasionally observed within the amorphous matrix (arrowed in fig. 1a). Figure $\mathrm{lb}$ shows a high resolution image of a single crystallite. The optical diffraction pattern (Fourier transform of image) taken from this region (fig. $1 \mathrm{~b}$ inset) shows evidence of crystallinity as indicated by the presence of discrete diffraction spots. These results represent the first actual observation of the initial crystallite nucleation layer in $\mathrm{CoCr}$ thin films.
Table

Film and orientation parameters. Key: $t=$ film thickness: $d$ $=$ average grain diameter; $d_{c}=$ column diameter: $\Delta \theta_{511}=X$ ray rocking curve half width; $\alpha_{\text {avg }}=$ average grain-to-grain misorientation; all films deposited on glass substrates

\begin{tabular}{lllll}
\hline$t$ & $\begin{array}{l}d_{g} \\
(\mathrm{~nm})\end{array}$ & $\begin{array}{l}d_{c} \\
(\mathrm{~nm})\end{array}$ & $\begin{array}{l}J \theta_{511} \\
(\mathrm{~nm})\end{array}$ & $\begin{array}{l}\alpha_{(\mathrm{ng})} \\
(0)\end{array}$ \\
\hline 10 & 19 & & & 10.1 \\
50 & 19 & 24 & 9.6 & 12.3 \\
100 & 211 & $16-5.5$ & 9.5 & 13.5 \\
500 & 21 & $19.5-31$ & 6.7 & 13.4 \\
\hline
\end{tabular}

Figures $2 \mathrm{a}-\mathrm{d}$ show typical plan views of the microstructure for films of thickness $10-500 \mathrm{~nm}$. From fig. $2 \mathrm{a}$, it can be seen that by $10 \mathrm{~nm}$, an

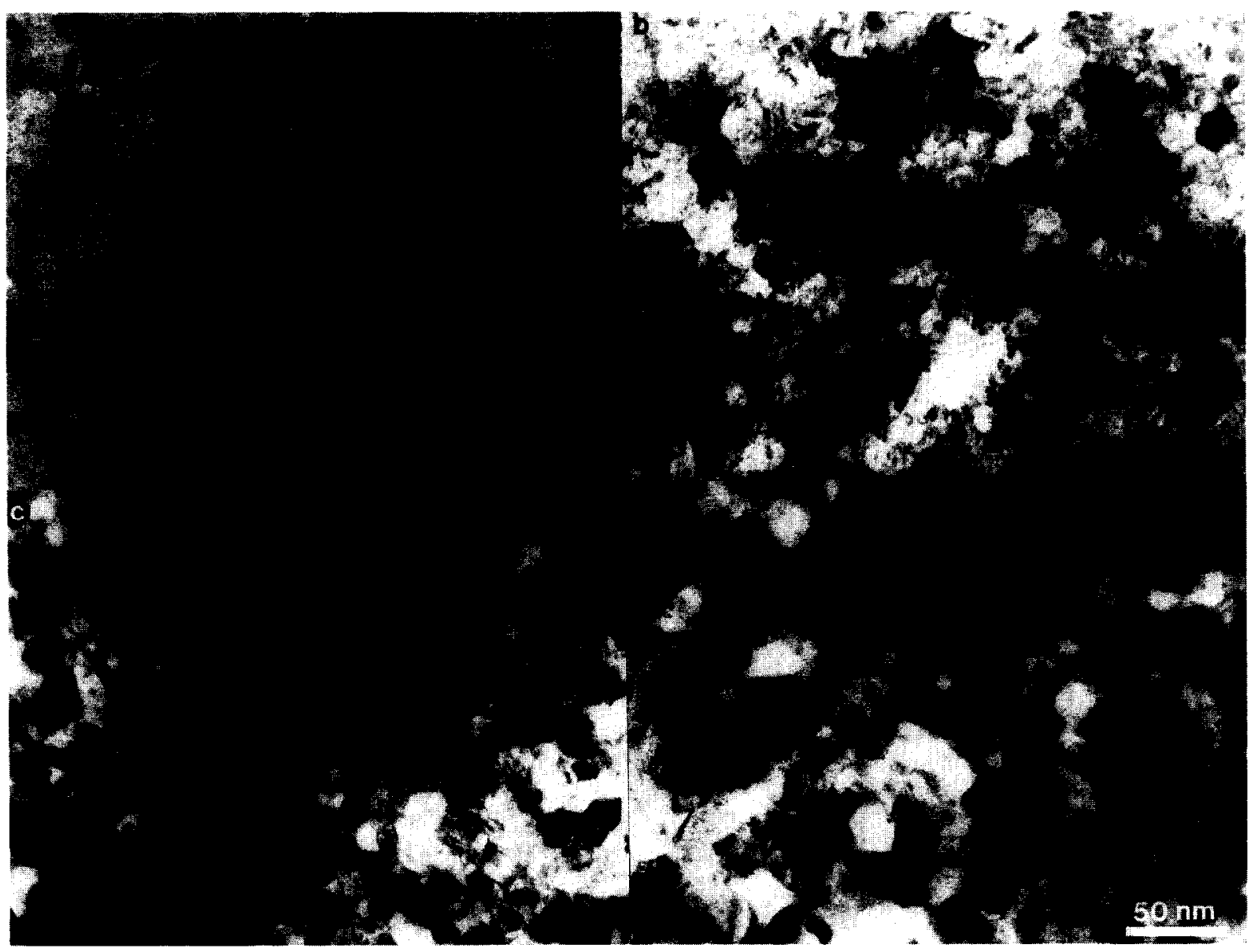

Fig. 2. TEM micrographs (plan view) of (a) $10 \mathrm{~nm}$, (b) $50 \mathrm{~nm}$, (c) $100 \mathrm{~nm}$, (d) $500 \mathrm{~nm}$ thick CoCr films. Note the presence of intragranular defects in (c) and (d). 
individual grain structure is starting to develop. In thicker films, these grains become more pronounced (figs. $2 b-d$ ). In addition, defects are observed within individual grains. These have been shown to be stacking faults, lying on the (0001) planes [11]. It is thought that these faults form to relieve the large in-plane film stress developed in film growth [11]. From table 1, we see that the average grain diameter is nearly constant with increasing film thickness, indicating that the final grain size is reached early on (by 50-100 nm thickness). This result differs from that reported in refs. [3-7], in which the grain size increased with increasing film thickness over a considerable film thickness range, but is similar to the results presented in refs. [8,9]. Figures $3 a-d$ show the corresponding selected area diffraction patterns taken from these films. It is of note that all of the patterns are similar. Comparison with a computed hcp ring pattern (fig. 4) reveals that only rings of the form $\{h k i 0\}$ are present, which indicates $c$-axis (0002) texturing normal to the film plane. This is also reflected in the observed $X$-ray rocking (about the (0002) peak) curve half widths $\left(\Delta \theta_{s 0}\right)$, also listed in table 1 , which are $10^{\circ}$ or less for all films for which an appreciable signal could be obtained.

In fig. 5, section views are shown for these

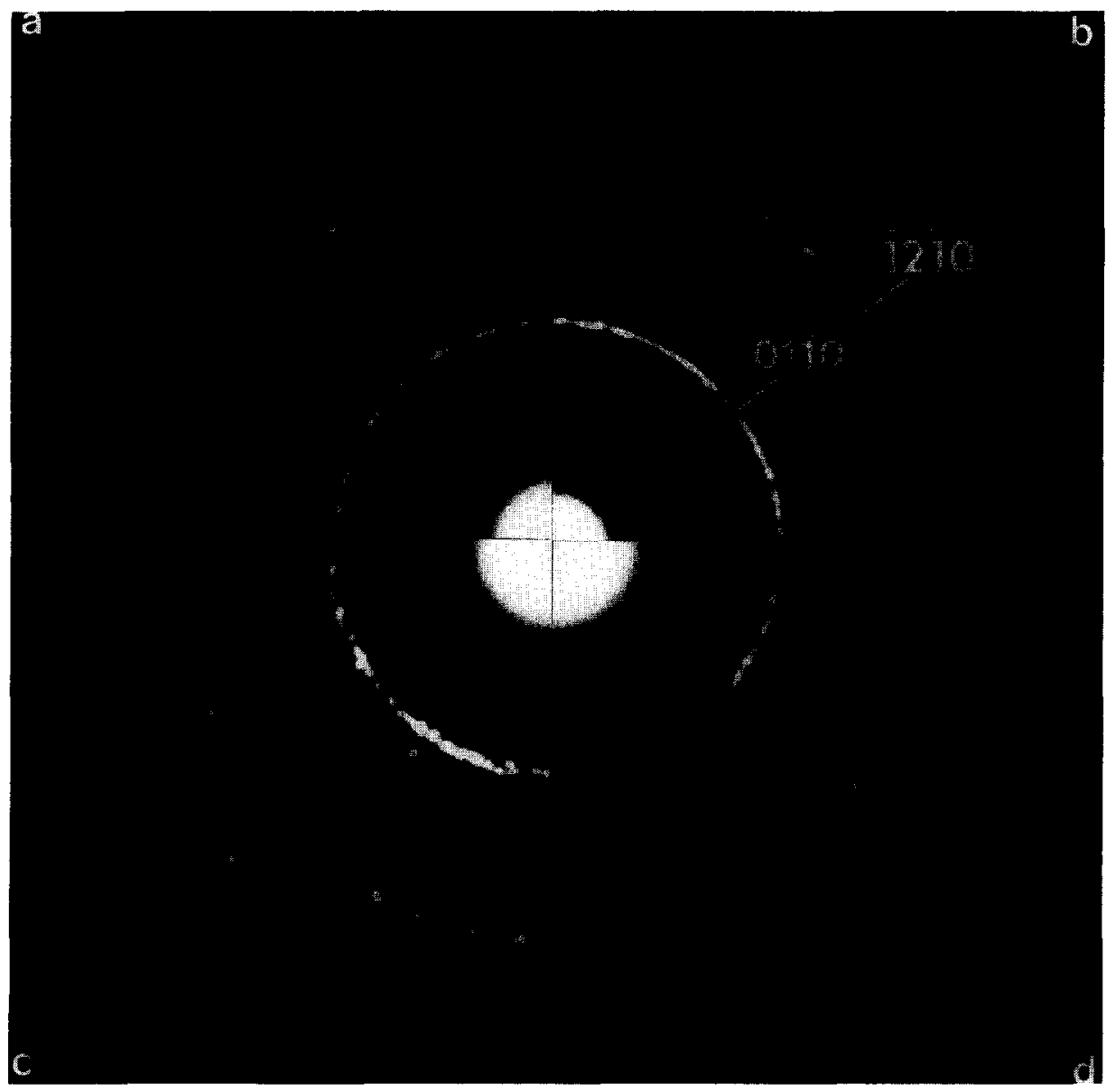

Fig. 3. SAD ring patterns taken from (a) $10 \mathrm{~nm}$, (b) $50 \mathrm{~nm}$, (c) $100 \mathrm{~nm}$, (d) $500 \mathrm{~nm}$ thick CoCr films. Note that all patterns are similar. 


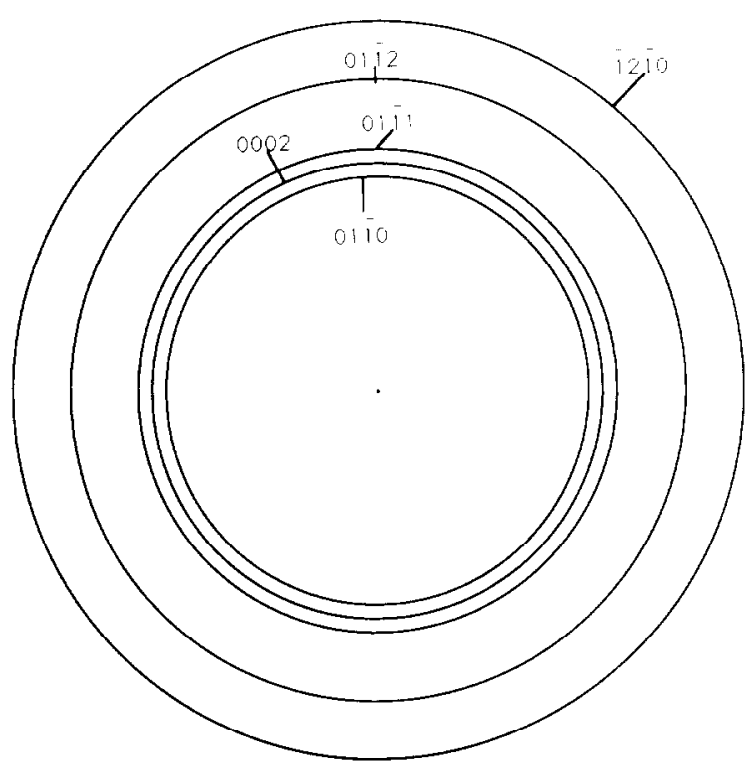

Fig. 4. Computed $\mathrm{SAD}$ ring pattern showing rings corresponding to the first few reflections of hcp CoCr. Comparison with fig. 3 reveals that only the ( $h k i 0)$ rings are present, indicating (0002) texturing normal to the film plane. same films. At $10 \mathrm{~nm}$ film thickness (fig. $5 \mathrm{a}$ ), a continous film is observed, with no distinguishable grain structure evident. This is consistent with the plan view microstructure for films of this thickness, in which the grains are barely distinguishable (fig. 2a). It is significant to note that these films are very strongly textured ( $c$-axis normal to the film plane), even though a columnar microstructure has not yet developed. By $50 \mathrm{~nm}$ (fig. 5b), a well defined column structure has formed. These columns are seen to extend through the film thickness, even in the thicker films (figs. $5 \mathrm{c}$ and $5 \mathrm{~d}$ ). From table 1, we see that the range of measured column diameters is similar to the average grain diameter encountered earlier. Thus it appears that each column is comprised a single grain, as can be inferred from the work of Hong et al. [8] for magnetron sputtered $\mathrm{CoCr}$ films on fused quartz. The aforementioned intragranular defects are also clearly visible in films of thickness $50 \mathrm{~nm}$ and greater (figs. $5 \mathrm{~b}-\mathrm{d}$ ).

a

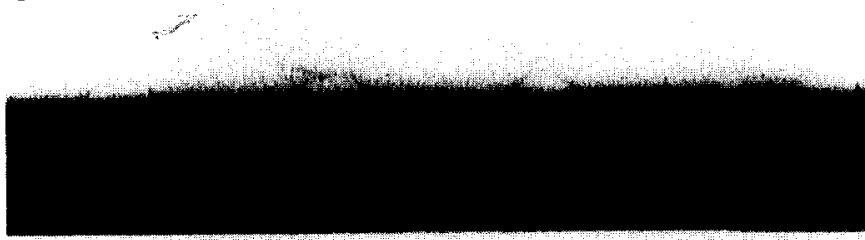

b

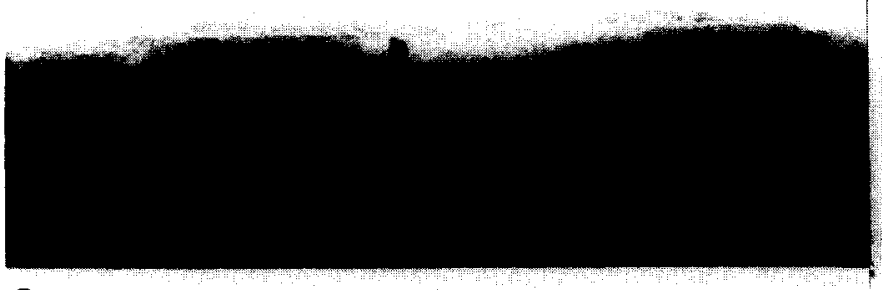

c

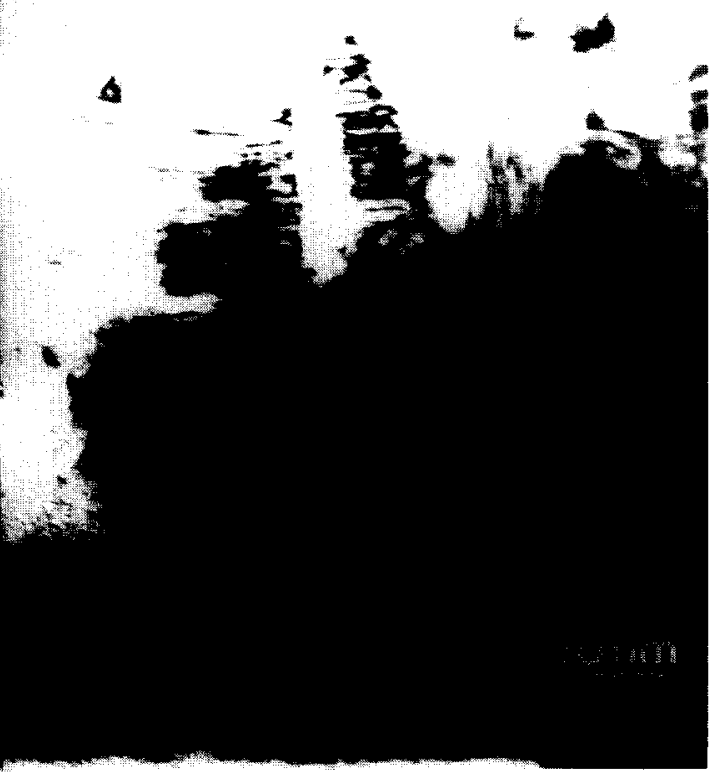

Fig. 5. TEM micrographs (section views) of (a) $10 \mathrm{~nm}$, (b) $50 \mathrm{~nm}$, (c) $100 \mathrm{~nm}$, (d) $500 \mathrm{~nm}$ thick CoCr films. Note the lack of column development in (a) and the presence of intragranular defects in (b), (c) and (d). 

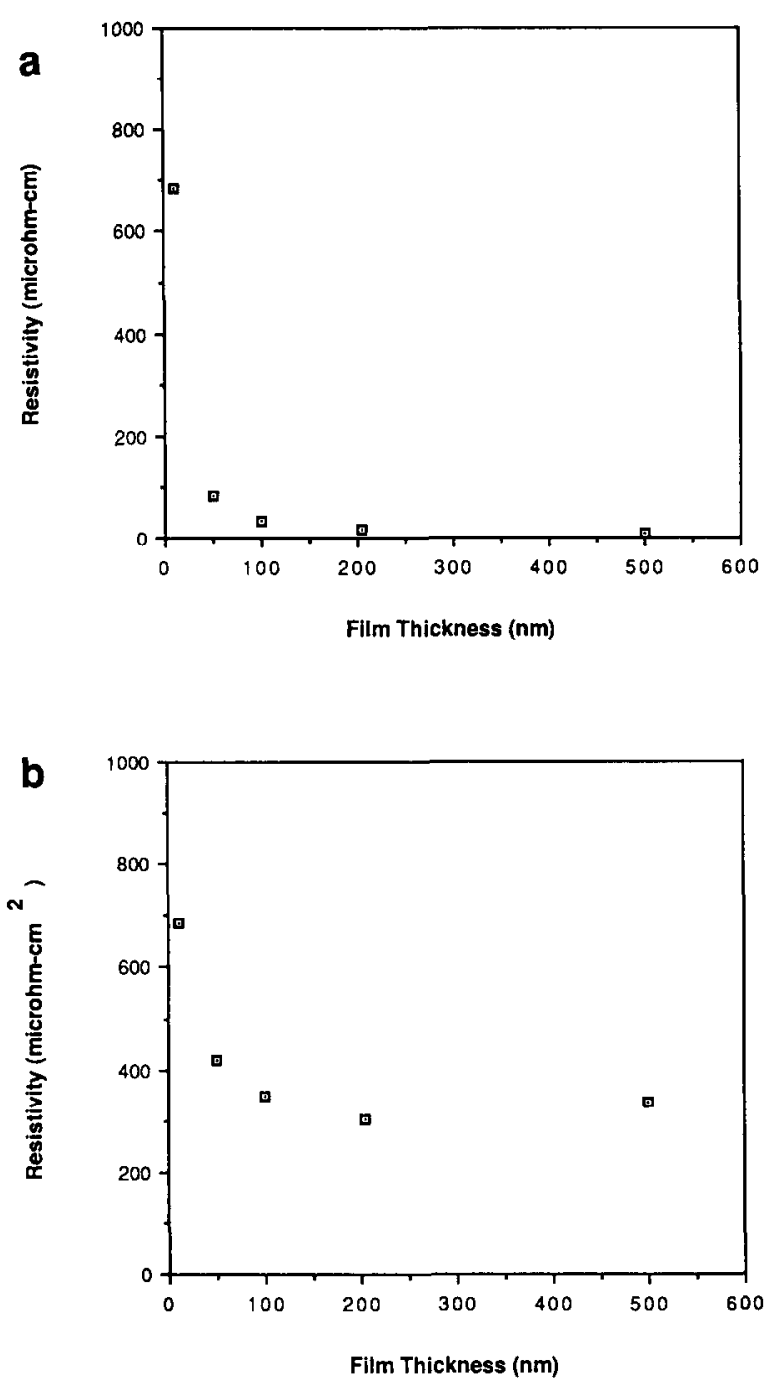

Fig. 6. Plot showing (a) electrical resistivity, (b) resistivity $\times$ film thickness as a function of film thickness. Note the sharp increase at small thickness values in (b), suggesting the presence of low angle boundaries.

At a film thickness of $500 \mathrm{~nm}$ (fig. $5 \mathrm{~d}$ ), the stacking fault density becomes quite high.

In fig. $6 \mathrm{a}$, the electrical resistivity is plotted as a function of film thickness. As shown, one observes large resistivity values in the $50 \mathrm{~nm}$ and, especially, the $10 \mathrm{~nm}$ thick films. It would be expected that the resistivity would increase with decreasing film thickness due to increased electron scattering from the (now closer) film free surface [12]. However, fig. $6 \mathrm{~b}$ shows that the product of the resistivity and the film thickness increases as well, indicating an additional contribution to electron scattering in the thinner films. This suggests that additional electron scattering centers are present in the thinnest films. One will also notice that the resistivity values do not change significantly beyond approximately $100 \mathrm{~nm}$ film thickness. This is consistent with the observation that column boundary widths remain constant with increasing film thickness above this value (table 1 and figs. 5b-d), the column boundaries presumably acting as electron scatterers. Close examination of the film microstructure in $10 \mathrm{~nm}$ films (fig. 7) reveals the presence of boundaries within the grains themselves. Electron microdiffraction (10 nm probe size) patterns taken across such boundaries (fig. 7 upper inset) reveal a small $\left(<10^{\circ}\right)$ rotational misorientation, looking down the (0002) zone axis. This is to be contrasted with microdiffraction patterns taken across the grain boundaries themselves (fig. 7 lower inset), which display larger misorientations. Figure 8 depicts a high resolution image taken from a single grain in a $10 \mathrm{~nm}$ thick $\mathrm{CoCr}$ film. The predominant lattice fringes are those corresponding to the $\{10 \overline{1} 0\}$ planes. This is confirmed by optical diffractogram analysis, which yields a large number of [0002] patterns (inset), indicating $c$-axis texturing normal to the film plane. Close examination of this micrograph reveals regions (arrowed, for example, in fig. 8) across which the $a$-axes are slightly misaligned. This provides the first direct evidence for the presence of low angle boundaries in $\mathrm{CoCr}$ thin films. The frequency of occurrence of these small angle boundaries decreases with increasing film thickness. At film thicknesses of 100-200 nm, such boundaries can no longer be distinguished. As shown in table 1, the average $a$-axis misorientation value $\left(\alpha_{\text {avg }}\right)$, measured by examining random (0002) electron microdiffraction patterns collected from a large number of grains, approaches $13.5^{\circ} \pm 2^{\circ}$ at the $100 \mathrm{~nm}$ film thickness. A value of $15^{\circ}$ would be expected if the $a$-axes were randomly distributed rotationally about the $c$-axis in the film plane. These low angle boundaries are thought to account for the increased electrical resistivity measured in the thinner films. 


\section{Discussion}

Most growth scenarios proposed for this material [13] involve the formation of a "transition layer", comprised of small, randomly oriented grains, followed by vertical growth of columns via an "evolutionary selection" mode [14]. In such a mode, the film texture is determined by the fastest vertical growth direction, often that normal to the closest packed plane [15] (here (0002)). This would account for the observed long range enhancement of the film texture $\left(\Delta \theta_{50}\right)$ seen in the thickest $(500 \mathrm{~nm}$ ) films (table 1$)$. In the present case, however, well oriented subgrains and strong $c$-axis texture (normal to the film surface) arise in films as thin as $10 \mathrm{~nm}$ (fig. 7). According to Movchan and Demchishin [16], when the substrate temperature is Icss than one-third of the melting point

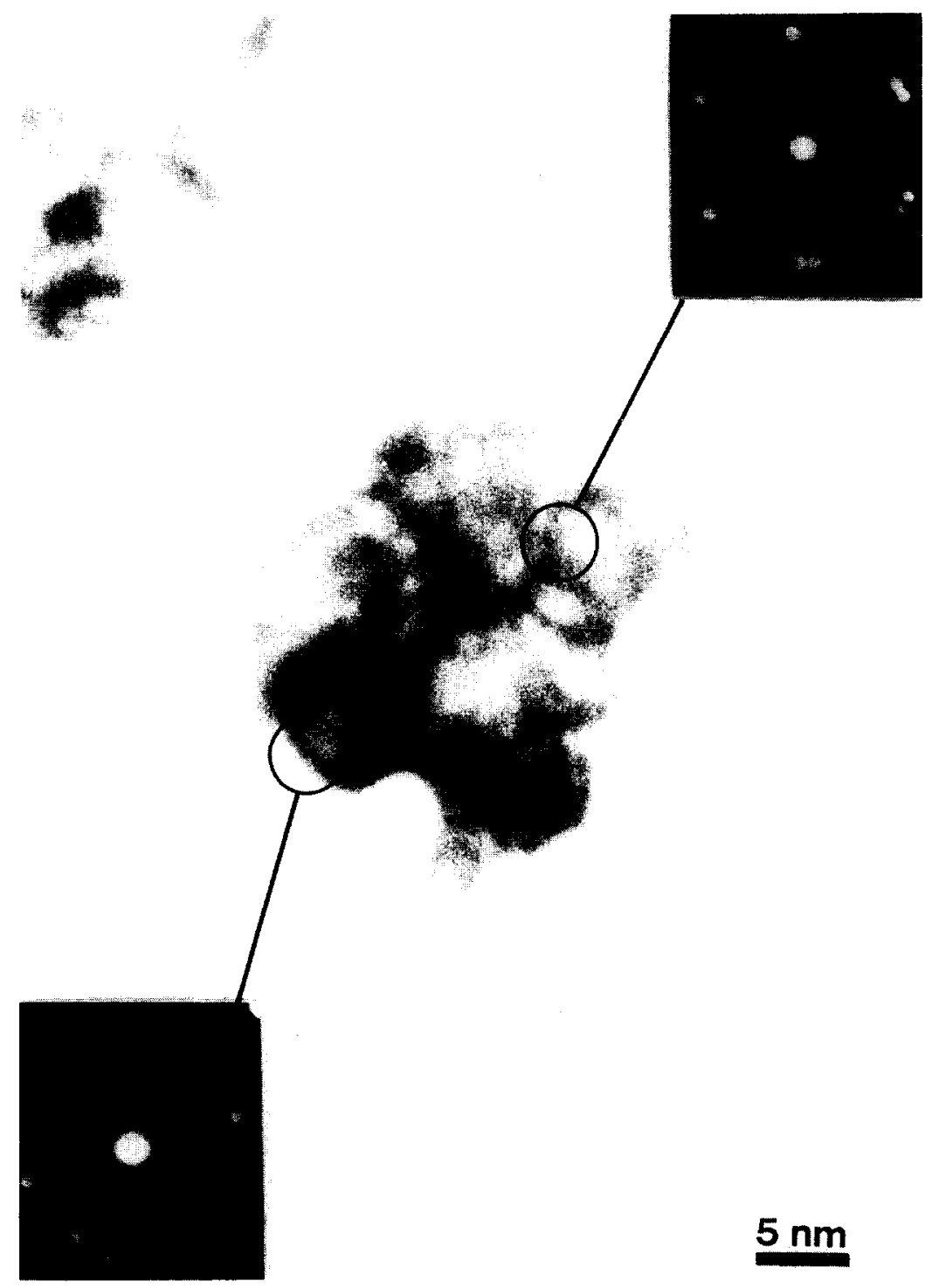

Fig. 7. Micrograph showing a single grain in a $10 \mathrm{~nm}$ thick CoCr film. Note the distinct boundaries within the grain. Insets represent electron microdiffraction patterns ( $10 \mathrm{~nm}$ probesize), taken across both low angle and grain boundaries. 
of the metal being deposited, the mobility of adatoms is low and incoming deposit atoms "stick" where they land, since the surface mobility is limited. This is seen to lead to the development of a continous, but noncrystalline film layer. When this layer reaches some critical thickness, crystallites (see figs. 1a and 1b) can develop by an athermal process [17]. For deposition temperatures less than one third the melting point of the deposit, athermal processes are often observed [18-20]. As small groups of atoms crystallize athermally from the amorphous precursor phase, they release a heat of crystallization which further stimulates crystallization until neighboring nuclei impinge (as per fig. 2a). The final grain size attained is therefore determined by the density of the crystallite nuclei rather than the relative growth rates in various crystallographic directions. Grovenor [17] also proposes that the transformation from precursor to stable structures may influence the orientation of the individual grains it produces through the effects of elastic

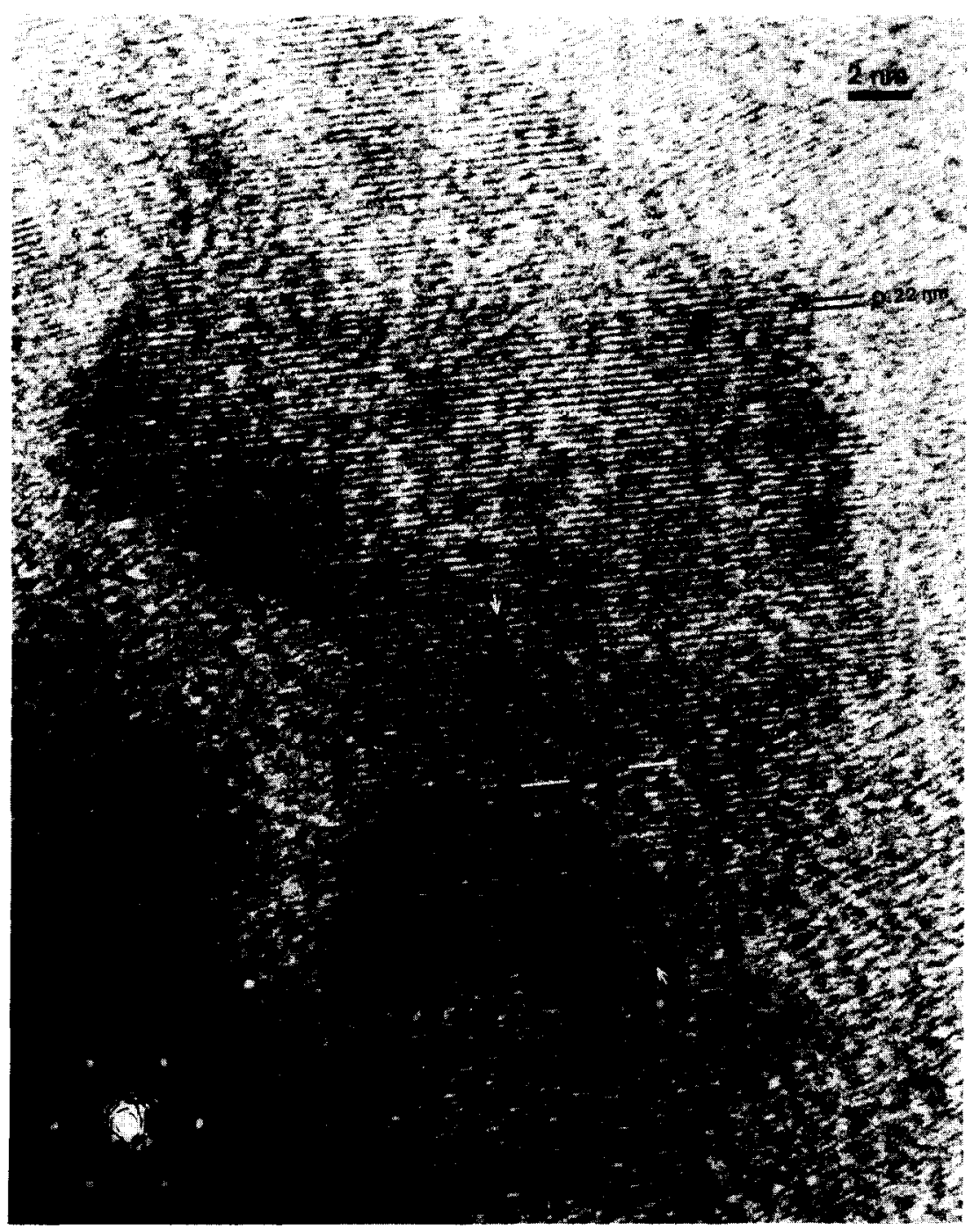

Fig. 8. HREM image of a single grain in a $10 \mathrm{~nm}$ thick $\mathrm{CoCr}$ film. Note the boundary that separates $(01 \overline{1} 0)$ planes of slightly varying orientation. Inset shows the corresponding optical diffraction pattern, displaying (0002) texture normal to the film plane. 
anisotropy. Grain boundaries in these initial stable grains would then be of the low angle (tilt or twist) type. This is indeed what is observed in the present case (figs. 7 and 8). Large values of in-plane film stress which display reversals in sign at small film thicknesses have recently been observed in sputtered $\mathrm{CoCr}$ films [21]. Although the exact mechanism of texture formation in the thinnest films remains unclear at this time, it is thought to be related to such stress effects.

\section{Summary}

Microstructural studies on magnetron sputtered $\mathrm{CoCr}$ thin films deposited on amorphous substrates reveal the following growth characteristics. The initial film deposit is predominantly amorphous, with occasional small crystallites forming by $5 \mathrm{~nm}$ thickness. By $10 \mathrm{~nm}$, the film is entirely polycrystalline and already highly $c$-axis textured normal to the film plane. At this thickness, one observes distinct intragranular low angle boundaries within the primary grains. By 50 $\mathrm{nm}$, well developed columns are seen in which one observes intragranular defects. By $100 \mathrm{~nm}$, the low angle boundaries are no longer present. Further growth occurs essentially in the vertical (normal to the film plane) direction.

Film growth scenarios based on evolutionary selection do not account for the observed microstructures in the thinnest films, and one must take into account the low surface mobility of adatoms at the low deposition temperatures encountered.

\section{Acknowledgements}

The author wishes to thank Prof. L. Berger of Carnegie Mellon University for the use of his electrical resistivity apparatus. Samples were produced by the author under Grant no. DMR8613386 from the Division of Materials Research. National Science Foundation.

\section{References}

[1] S. Iwasaki and Y. Nakamura, IEEE Trans. Magn. MACi $1.3(1977) 1272$.

[2] T. Wielinga, PhD Dissertation, Twente Univ, of Tech. Enschede, The Netherlands (1983).

[3] J.C. Lodder, T. Wielinga and J. Worst. Thin Solid Films $101(1983) 61$.

[4] C. Hwang, D.E. Laughlin, P.V. Mitchell, A. Layadi, K.R. Mountfield, J. Snyder and J.O. Artman, J. Magn. Magn. Mater. 5457 (1986) 1676.

[5] M. Futamoto, Y. Honda, H. Kakibayashi, T. Shimotsu and K. Yoshida, Jpn. J. Appl. Phys. 24 (1985) L460.

[6] P.J. Grundy, M. Ali and C.A. Faunce, IEEE Trans. Magn. MAG-20 (1984) 794.

[7] J.W. Lee, B.G. Demczyk, K.R. Mountfield and D.F. Laughlin, J. Appl. Phys. 61 (1987) 3813.

[8] M. Hong, S. Nakahara, R.B. van Dover and T. Boonc. Appl. Phys. Lett. 19 (1988) 1308.

[9] H. Cura and A. Lenhart, J. Magn. Magn. Mater. 83 (1990) 72.

[10] J.W. Lee, B.G. Demczyk, K.K. Mountfield and D.F. Laughlin, IEEE Trans. Magn. MAG-23 (1987) 2455.

[11] K. Hono. B.G. Demczyk and D.E. Laughlin, Appl. Phvs. Lett. 55 (1989) 229.

[12] E.H. Sondheimer, Adv. Phys. 1 (1952) 1

[13] L. Byun, J.M. Silverstein and J.H. Judy, unpublisbed research.

[14] A. Van der Drift, Philips Res. Rep. 22 (1967) 267.

[15] E. Bauer, in: Single Crystal Films, eds. M.H. Fanncombe and H. Sato (MacMillan, New York, 1964) 43.

[16] B.A. Movchan and A.V. Demchishin, Fizika Metall. 28 (1989) 83.

[17] C.R.M. Grovenor, H.T.G. Hentzell and D.A. Smith. Acta. Metall. 32 (1984) 773

[18] N.J. Petch. J. Iron Steel Inst. 147 (1943) 444.

[19] P. Gaunt and J.W. Christian, Acta Metall. 7 (1959) 534.

[20] J.S. Bowles, Trans. Am. Inst. Min. Eng. 191 (1951) 44.

[21] B.G. Demczyk and J.O. Artman, J. Phys. D, in press. 